\title{
O "se-movimentar" e a temporalidade: uma aproximação entre dança e linguagem
}

\author{
The "self-move" and temporality: \\ an approximation between dance and language \\ El "mover-se" y la temporalidad: \\ una aproximación entre danza y lenguaje \\ Danieli Alves Pereira Marques ${ }^{1}$; Elenor KunZ ${ }^{2}$ \\ UNIVERSIDADE DO EST ADO DE SANTA CATARINA, UDESC, FLORIANÓPOLIS-SC, BRASIL \\ Universidade Federal de Santa Maria, UFSM, SANTa Maria-RS, BraSIL
}

\begin{abstract}
RESUMO
O texto faz uma aproximação da dança na perspectiva da linguagem com o "se-movimentar" e suas relações com a temporalidade. Discute sobre os lugares da exploração dos gestos, da aprendizagem da cultura de movimento e da criação nas experiências com a dança no contexto pedagógico. Entrelaçando tempo e "se-movimentar", observamos que a expressão criadora se dá na troca eu-outro-mundo. $O$ entendimento de um tempo estendido, não fragmentado, nos mostra que uma motricidade original se projeta entrecruzando passado-presente-futuro. Nessa perspectiva, podemos pensar numa prática de ensino que não opõe as transcendências de limites da aprendizagem (forma direta, forma aprendida, forma criativa inventiva), uma vez que há o jogo da transitividade entre elas.
\end{abstract}

Palavras-chave: Dança. Linguagem. “Se-Movimentar”. Temporalidade.

\begin{abstract}
The text draws an approximation of dance from the perspective of language with the "self-movement" and its relations with temporality. It discusses about the places of the exploration of the gestures, the learning of the culture of movement and the creation in the experiences with the dance in the pedagogical context. Interweaving time and "self-movement", we observe that the creative expression takes place in the I-other-world exchange. The understanding of an extended, non-fragmented time shows us that an original motricity projects itself crosscrossing past-present-future. In this perspective, we may think of a teaching practice that does not oppose the transcendences of learning limits (direct form, learned form, inventive creative form), since, between them, there is the play of transitivity.
\end{abstract}

Keywords: Dance. Language. "Self-Move”. Temporality.

\section{RESUMEN}

El texto realiza una aproximación de la danza en la perspectiva del leguaje con el "mover-se" y sus relaciones con la temporalidad. Discute sobre los lugares de la exploración de los gestos, del aprendizaje de la cultura de movimiento y de la creación en las experiencias con la danza en el contexto pedagógico. Entrelazando tiempo y "mover-se", observamos que la expresión creadora se da en el intercambio yo-otro-mundo. La comprensión de un tiempo extendido, no fragmentado, nos muestra que una motricidad original se proyecta entrecruzando pasado-presente-futuro. En esa perspectiva, podemos pensar en una práctica de enseñanza que no opone las trascendencias de límites del aprendizaje (forma directa, forma aprendida, forma creativa inventiva), una vez que existe el juego de la transitividad entre ellas.

Palabras clave: Danza. Lenguaje. "Mover-Se". Temporalidad.

\footnotetext{
${ }^{1}$ Professora substituta da UDESC. E-mail: edf.danieli@gmail.com

${ }^{2}$ Professor Aposentado da UFSC e Professor Visitante da UFSM. E-mail: elenkunz@ terra.com.br
} 


\section{INTRODUÇÃO}

Nesse breve escrito, embora não tenhamos pretensões de aprofundar o conceito de linguagem em Merleau-Ponty, buscamos, em alguma medida, possibilidades para a problematização dessa temática voltada ao campo pedagógico da dança. Pensar a dança na perspectiva da linguagem implica levar em consideração a "dimensão do tempo como materialidade experimentada" (TIBURI; ROCHA, 2012, p. 73), pois as formas de expressão, sejam quais forem, se dão no tempo.

Aproximando a experiência da dança à experiência da linguagem - interrogamos sobre os lugares da exploração dos gestos, da aprendizagem da cultura de movimento e da criação nas experiências com a dança nesse contexto. Como conciliar tais ações sem pretensão de sufocamento e rivalidade entre esses momentos?

Essa interrogação deságua na teoria do "se-movimentar" (KUNZ, 2012; 1994). Por ela, somos convidados a nos mover, buscando espaços no pensamento do autor que possam articular-se às reflexões sobre a experiência da dança como linguagem. Mesmo que o conceito de linguagem não esteja em foco e não seja almejado quando se expõe tal proposta. Dizemos isso porque, em meio às leituras disponíveis sobre o "semovimentar", encontra-se uma ponderação sobre esse aspecto, feito por Ghidetti (2012). Essa dissertação, após analisar as produções de Kunz, apontando seus limites e possibilidades, menciona a falta de um diálogo mais fecundo com a última obra de Merleau-Ponty e, exatamente pelo fato de ela ter centrado em "Fenomenologia da percepção", deixaria escapar, entre outros aspectos, a reformulação de conceitos, como a extensão da compreensão de corpo para a de carne, e mudanças relativas ao tema da linguagem.

Não será nossa tarefa discutir quais conceitos da fenomenologia se manifestam ou não na teoria do "se-movimentar" e tampouco traçar um panorama histórico sobre sua origem e percurso até chegar à Educação Física brasileira. Cabe apenas destacar que, no Brasil, essa proposta foi exposta por Kunz em 1991, e tem seus princípios pedagógicos e filosóficos respaldados, principalmente, nos holandeses Gordijn, Tamboer e Buytendkijk, além do alemão Trebels, o que subsidia o desejo de impulsionar uma teoria do movimento humano que fuja da concepção empírico-analítica, pautado no rendimento, na competição, na sobrepujança, na exclusão, na comparação, entre outros aspectos presentes, notoriamente, no ensino dos esportes.

Se acompanharmos os escritos de Kunz, buscando encontrar aspectos da última obra de Merleau-Ponty (leia-se aqui o tema da linguagem) entrelaçados à teoria do "semovimentar", podemos concordar com as considerações de Ghidetti (2012). Por outro lado, se fizermos o caminho inverso, partindo das nossas experiências com o "semovimentar", percebemos ser possível, nas membruras visíveis e invisíveis, encontrar pontos de encontro para o início de um possível aconchego.

Dito isso, façamos das palavras de Valéry (2007), as nossas próprias palavras.

\footnotetext{
Peço desculpas por expor-me assim diante de todos vocês; mas acho mais útil contar aquilo por que passamos do que simular um conhecimento independente de qualquer pessoa [...] Nada direi que vocês não saibam; mas direi talvez em uma outra ordem (p. 196).
}

O texto será ultrapassado por experiências vividas, intervenções pedagógicas correspondentes a aulas de dança para crianças e adolescentes, em um projeto extracurricular, junto a escolas da rede pública de ensino. Tal proposta foi permeada pelo desejo de possibilitar uma aprendizagem que não sufocasse a atmosfera brincante 
O "se-movimentar" e a temporalidade

já presente nas crianças. No entanto, também, reconhecendo que, nem por isso, podemos abrir mão de encontrar caminhos para possibilitar o acesso aos procedimentos técnicos das diferentes formas de dançar.

Pensar a exploração, a aprendizagem e a criação dos gestos a partir da dimensão temporal, nos auxilia a principiar uma possível compreensão do tema linguagem em Merleau-Ponty, além disso, pode-se presumir por que o filósofo tanto aproximou arte e linguagem.

\section{MOVIMENTO-EXPERIÊNCIA-EXPRESSÃO}

Se podemos falar da experiência da linguagem, podemos abrir o diálogo para pensar a possibilidade da experiência do movimento? ...matéria-prima para a existência da dança (DANTAS, 1999). Se concordarmos com Merleau-Ponty (1999) que a expressão é criadora, vemos que, em todas as manifestações gestuais, a expressão é sempre inseparável do expresso. Assim sendo, não existe expressão anterior ao gesto; nesse caso, para o filósofo, o sentido é o movimento total da expressão, da fala, da música, da dança, da poesia... E, se assim ocorre, se a fala faz brotar significação encarnada no gesto, é graças à experiência falante que, ao se dar, enuncia também, um estilo, articular e sonoro, não permitindo que a expressão falante se reduza à soma de enunciados, ou à simples tradução do pensamento, uma vez que, como bem assinala Müller (2001), os pensamentos possuem relação de não-independência com as articulações gestuais, pois até mesmo nossos pensamentos mais familiarizados, já falados, renascem, ou em nosso corpo ou no corpo de outro falante.

Como apresenta Merleau-Ponty (1999), não há a elaboração de uma expressão ocorrida dentro (pensamentos) e uma representação que se manifesta fora (palavras), na medida em que o próprio orador, enquanto fala, não pensa em cada palavra para fazê-lo, pois, se isso ocorresse, nada seria dito. Isso porque o pensamento não existe fora do mundo e fora das palavras.

O que nos engana a respeito disso, o que nos faz acreditar em um pensamento que existiria para si antes da expressão, são os pensamentos já constituídos e já expressos dos quais podemos lembrar-nos silenciosamente [...] mas, na realidade, esse pretenso silêncio é sussurrante de falas (p. 249).

O pensamento do orador, anuncia Merleau-Ponty (1999), “[...] é vazio enquanto ele fala" (p. 245). Diz ainda que, quando nos voltamos à leitura de um escrito, se a expressão nos envolve, não temos um pensamento à margem do próprio texto, as palavras nos ocupam por inteiro. Eis aí o estado de presença tão almejado na experiência da dança que, quando ocorre, sabemos que dançamos esquecidos de nós mesmos, momento fecundo em que damos forma à experiência, deixando revelar nosso ser-na-dança, nosso estilo, que é o que torna possível toda significação, assinala Merleau-Ponty (1974).

Se dizer não é colocar uma palavra sobre cada pensamento (MERLEAU-PONTY, 2004), podemos, então, supor que o mesmo ocorre com o movimento? Como ocorre a expressão do movimento na dança?

Fraleigh (1996) enuncia um instante de unificação-na-ação que ocorre quando dançamos, momento presente, que implica uma unidade do 'eu' e do corpo em ação, pois o corpo está implicado em, ao invés de separado da vontade. Gil (2004), diz existir na dança, uma ação que pertence à presença do corpo em totalidade no próprio momento em que se manifesta, instante que "[...] a consciência do movimento se torna movimento da consciência" (p. 23). Dantas (1999) assinala que a presença corporal do 
bailarino se intensifica quando sua atenção é empregada à sensação do movimento, uma vez que "[...] dançar é imprimir no corpo a sensação do movimento" (p. 110, grifo da autora). Louppe (2012) lê a presença na dança como uma qualidade de "estar lá", "[...] presença total no instante, sem prazo ou antecipação estipulada" (p. 163).

Poderíamos dar continuidade à lista de autores que mencionam o momento da expressão, ou um estado de presença na dança, mas esses já são suficientes para nos mostrar que há um espaço de compreensão no próprio movimento, que não se limita ao pensamento, ou melhor, que não é submisso a ele. Observamos que todos os autores e autoras que trouxemos, fazem menção a uma espécie de ação, atenção, ou concentração, sinalizando o momento da experiência da expressão. Trata-se de um "compreender-omovimento-pelo-agir" (KUNZ, 2012), movimento-compreensão, que - numa proposta gadameriana - é ser. Não apenas compreendemos o movimento, ele é compreensão, pre-sença (Dasein), que suscita no exprimir nosso estilo, legitimando nossa maneira particular de ser, tratar e interpretar o mundo (MERLEAU-PONTY, 2004), que elucida traços incomparáveis, e denuncia nossas variações no olhar, no tocar, no falar, no dançar, que confirmam: "se-movimentar" é saber humano, possui sua especificidade e constitui-se tão digno quanto o pensar.

Por esse motivo, talvez, Merleau-Ponty (1999) não se tenha cansado de nos lembrar: "[...] o movimento não é o pensamento de um movimento, e o espaço corporal não é um espaço pensado ou representado" (p. 192). Quando nos movemos, espaço e tempo se fazem em nós. Nessa direção, Gil (2004) expõe que bailarinos quando dançam, não percorrem distâncias objetivas e nem tempos cronológicos dados, pois a dança produz unidade de espaço-tempo, de modo que, segundo Saraiva (2005), ela consiste em uma forma dinâmica e única, o que permite que seja em cada experiência criada e recriada novamente.

Valendo-nos da constatação de Palmer (2006), podemos ver com ele que a formação das palavras - e acrescentamos a construção dos movimentos - não é um produto da reflexão, mas sim da experiência, posta pelas exigências dela própria, que revela o ser em uma situação.

Isto é o que nos propõe Kunz (2012), quando mostra ser o "se-movimentar" um diálogo. Há um ser-no-movimento que questiona o mundo e suas relações com ele e, na medida em que interroga, é ao mesmo tempo interrogado, permitindo o movimento ser resposta - e incluímos pergunta - sempre em transform-ação, que se dão, conforme Kunz, em diferentes ocasiões pessoais-situacionais, o que permite conferir no diálogo uma significação tanto subjetiva quanto objetiva.

Cabe-nos dizer que, se o "se-movimentar" é diálogo, podemos emprestar o pensamento de Gadamer (2012) para sinalizar que nessa convers-ação, o que surgirá, ninguém pode saber de antemão. A linguagem que nela se emprega carrega em si sua própria verdade, desvela e deixa surgir algo que é, e não se representa.

\section{ESPONTANEIDADE, APRENDIZAGEM, CRIAÇÃO: A CONJUGAÇÃO DAS DIMENSÕES TEMPORAIS NA EXPERIÊNCIA DO MOVIMENTO}

Kunz (2012), ao falar sobre a aprendizagem do movimento, apresenta um processo, que se dá a partir de três formas - direta, aprendida e criativa/inventiva ${ }^{3}$-, nas quais experienciamos a possibilidade de transcender limites pelo "se-movimentar".

\footnotetext{
${ }^{3}$ Formas de aprendizagem apresentadas com base nos holandeses, Gordijn e Tamboer, autores que tiveram como pano de fundo de seus estudos a fenomenologia de Merleau-Ponty, especialmente a obra Fenomenologia da Percepção.
} 
Dentre os elementos inspiradores dessa proposta pedagógica, por ora destacaremos essas três formas (direta, aprendida, criativa/inventiva), já que, esses procedimentos fundamentaram as experiências que descreveremos. Podemos dizer que, ao nosso olhar, essas etapas de aprendizagem conjugam as dimensões temporais na experiência do movimento, sem rivalidade. E isso pode tornar-se condição particular para proporcionarmos um vínculo com o entendimento de linguagem em MerleauPonty.

Enfrentando a dificuldade de definir o tempo, Merleau-Ponty (1999) nos adverte que isso decorre do fato de ele não se constituir objeto de nosso saber, ele é mesmo da ordem da experiência, dimensão de nosso ser, campo de presença em sentido amplo. Considerando a metáfora de Heráclito, Merleau-Ponty pondera que ela só persiste porque nós colocamos no riacho um observador testemunhando seu curso. Isso quer dizer que "[...] o tempo supõe uma visão sobre o tempo. Portanto, ele não é como um riacho, ele não é uma substância fluente. [...] Ele nasce de minha relação com as coisas" (p. 551).

Estamos diante de um fluxo temporal, que não é substância, que não se desvincula do passado e do futuro, mas que, sobretudo, não se relaciona com essas dimensões de forma fragmentada. O tempo como por vir, assinalado por Merleau-Ponty, desliza no passado e no presente, “[...] não é uma linha, mas uma rede de intencionalidades" (1999, p. 558).

Nas experiências dançadas com as crianças, percebemos como se tece uma temporalidade na aprendizagem dos gestos e, com isso, reconhecemos, junto com Bardet (2014) que, entrando no terreno da temporalidade, podemos esclarecer os problemas de fronteiras estanques entre composição, escrita e improvisação na dança, nesse caso, entre espontaneidade, aprendizagem, criação. Estamos centrando na dança, mas isso também se estende ao conhecimento das demais manifestações da cultura de movimento que compõem os conteúdos da Educação Física e estão disponíveis para acesso.

Em primeiro lugar, destacamos o fato de que somente podemos separar a estruturação dessas três etapas de aprendizagem para uma possível compreensão anterior ou posterior à experiência, uma vez que há reversibilidade entre elas e não conseguimos definir com precisão onde elas se encontram, começam ou acabam. Em um segundo momento, entendemos que compreender a experiência do movimento a partir da perspectiva do tempo, nos faz superar interpretações que o inscrevam em uma subjetividade que seja transparência de si, uma aprendizagem como pura cópia e repetição, e uma criação fruto de uma espontaneidade apartada do mundo. Entrelaçando tempo e "se-movimentar", podemos ver que o originário não diz respeito ao "retorno às coisas mesmas" como anulação da cultura, visto que, ao contrário, se trata de recomeço, reinauguração. O originário se dá no entre, na continuidade de um tempo e no seu afastamento, na fissura pela diferença de nossos gestos, de nosso estilo, portanto, de nossa troca eu-outro-mundo, uma espécie de câmbio que inaugura e celebra o que está por vir.

Retomando as formas de aprendizagem, a "transcendência de limites pela forma direta" envolve uma intenção espontânea de movimento, não pré-planejada, direta, um saber corporal que é pré-reflexivo (KUNZ, 2012). Para essa etapa, tratava-se da proposição de situações com ausência de modelo, imagem ou qualquer referência de movimento. As situações eram lançadas como interrogações para que as crianças respondessem a partir de seus próprios repertórios de movimento, abrindo 
possibilidades para que elas investigassem e se descobrissem nos gestos ${ }^{4}$. Podemos trazer como ilustração, uma indagação que fazíamos a elas, quando as questionávamos como poderíamos atravessar um determinado espaço eliminando o andar de forma tradicional, esse verticalizado que todos já conhecem. Ao propormos isso, imediatamente surgia o correr, o pular, muitas formas de rolar, o gatinhar, o rastejar, o andar em quatro apoios... Feitas tais descobertas, solicitávamos que, em uma próxima ocasião, a partir das formas já vivenciadas, elegessem outras direções, diversificassem os caminhos, não se fixando somente em uma reta; mais adiante, solicitávamos que variassem as velocidades, e também brincassem com os fluxos dos gestos (ora rápido, ora lento, ora interrompido, ora contínuo). Aos poucos, as crianças incorporavam outras energias, impulsos, vetores, deixavam algo acontecer, experienciando-se, saindo da zona de conforto, dos caminhos que já conheciam.

Nessa etapa, é importante destacar que as crianças já possuem seus repertórios de movimentos quando chegam até nós. Pular, rolar, deslizar, rodar, correr, caminhar, balançar, chacoalhar são apenas alguns verbos que se materializam no "se-movimentar" da criança. Embora eles sejam hoje espontâneos, trata-se de uma espontaneidade adquirida em um contexto não institucional, já que, se pensamos pela perspectiva do tempo, quando nascemos o assumimos e, conquanto nossa percepção estilize nossa forma única de comportar-se, nosso estilo é aprendido no partilhamento do mundo, no partilhamento dos gestos, na transitividade de um corpo ao outro. Somos habitados por uma visão anônima, geral, porque estamos ligados pela comunhão carnal. Com a reversibilidade do visível, do sensível e do tangível abre-se um ser intercorporal (MERLEAU-PONTY, 2007).

À criança é possibilitado o acesso ao passado e, nesse processo, a subjetividade, nos ensina Merleau-Ponty - não é identidade imóvel, "[...] para ser subjetividade, é lhe essencial, assim como o tempo, abrir-se a um Outro e sair de si” (1999, p. 571). Se o tempo se abre em todas as suas dimensões, a criança se abre ao outro, dividindo gestos habituais, cotidianos, esses com os quais temos um saber de familiaridade e, não nos oferecem posições no espaço objetivo (MERLEAU-PONTY, 1999).

O que fazemos, com esses movimentos habituais, é potencializá-los quando os trazemos para o contexto das especificidades da dança, considerando aqui, por exemplo, a atividade já descrita. Os gestos já adquiridos, em função do encontro, do acaso da experiência, se abrem e "[...] fazem vibrar as nossas evidências habituais até desajuntálas" (MERLEAU-PONTY, 2007, p. 103).

Os repertórios de movimentos transpostos para o "plano da ficção" (BERNARD, 2001), ou para o plano do "gesto virtual" (LANGER, 1980), já não são os mesmos do cotidiano, e com sentidos sempre temporários e variáveis, inauguram um tempo original, irrepetível, temporalidade instituinte. Uma vez que não há certezas nem escolhas pré-definidas, tudo se passa pelo entre, entre eu-outro-dança, entre eu-outroproposta. Aí temos o inesperado, o desespero dos movimentos ganhando outras formas.

As transcendências de limites pelo movimento, fundamentadas na perspectiva do tempo, nos fazem perceber que as crianças não abandonaram suas experiências vividas; o que fazem é reabri-las, a partir dos desafios presentes, dando-lhes uma nova configuração. São respostas de movimento, no instante que não saem do tempo, há um tempo singular, construído no deslizamento (passado-presente-futuro). Há jogo no encontro, e então a capacidade criadora e instituinte que move o fluxo. Por isso o corpo, afirma Merleau-Ponty, é um nó de significações vivas, "[...] por vezes forma-se um

\footnotetext{
${ }^{4}$ As experiências pedagógicas relatadas foram desenvolvidas em um Projeto de Dança extracurricular, realizado por uma instituição de ensino superior (Uniguaçu), em parceria com escolas da rede pública. Tiveram como mediador um dos autores.
} 
O "se-movimentar" e a temporalidade

novo nó de significações: nossos movimentos antigos integram-se a uma nova entidade motora [...]" (MERLEAU-PONTY, 1999, p. 212), a aprendizagem, a invenção de um novo gesto,

[...] ou a nova intenção significativa só se conhece a si mesma recobrindo-se de significações já disponíveis, resultando de atos de expressão anteriores. As significações disponíveis entrelaçam-se repentinamente segundo uma lei desconhecida, e de uma vez por todas um novo ser cultural começou a existir (MERLEAU-PONTY, 1999, p. 249).

Essa temporalidade, encarnada, movente, é também observada tanto na "forma aprendida" quanto na "forma criativa/inventiva". A forma aprendida, acenando para a transcendência de limites pela aprendizagem, diz respeito à imitação da intenção de um gesto e não da forma "exata" (KUNZ, 2012). Esse momento comportava sequências de movimentos trazidas para as crianças, possibilitando, então, o acesso a elementos do vasto campo de repertórios dançantes (por exemplo, dança jazz e danças urbanas), sem desconsiderar, com isso, as possibilidades e o tempo de aprendizagem de cada grupo. Essa experiência de movimento era caracterizada pela sua abertura quanto ao seu resultado. Isso quer dizer que entre as intenções de nossos gestos e o das crianças havia diálogo, dando-se aqui, o que Almeida, Fensterseifer e Bracht (2014), chamam de dignidade à contingência do movimento que, dado o seu caráter incerto, não se reduz apenas ao estereótipo. Ainda com os autores, vemos que a diferença atuante no movimento (das crianças), não se constitui um defeito, mas a própria condição da expressão, o que nos leva novamente ao plano da linguagem. Predomina nesse espaço a virtude significante, na qual não há referência a significações para si já claras (MERLEAU-PONTY, 1999), “[...] a linguagem não é como uma prisão onde estejamos presos, ou como um guia que precisaríamos seguir cegamente" (MERLEAU-PONTY, 2004, p. 116).

A expressão não é pensada na imutabilidade de um sentido imposto por tal gesto em que as crianças tivessem que alcançar. Trata-se de reconhecer a instabilidade, a impermanência do movimento, sua capacidade de se manifestar sempre de novo, de outras formas, em estado provisório. Talvez possamos falar aqui no "aspecto da tradução da linguagem conjugada com o jogo" (GADAMER, 2012), ou ainda, na "traduzibilidade entre as linguagens" (FENSTERSEIFER; PICH, 2012).

Poderíamos dizer, com a ajuda de Gadamer, Fensterseifer e Pich, que se nossos gestos são pensados como uma linguagem ainda estrangeira para as crianças, elas podem transferi-los para a direção de seus próprios dizeres. A expressão do gesto infantil não é simplesmente imprecisa, algo que precisaria ser melhorada; ao contrário, essa condição é justamente a possibilidade, a potência, o impulso para a transformação, para a diferença. No jogo de aprender uma linguagem ainda desconhecida, repousa a saída de si e a abertura ao outro. Quando os gestos vêm à dança das crianças, na ação, se dão na "originalidade" do dizer; na simples repetição eles se esvaem; não há nada que determine exatamente essa ação e que dê aos movimentos, antes de tudo, uma direção, depois uma conclusão clara e certa (VALÉRY, 2011).

Como diz Almeida (2016, p. 74), com o apoio de Gadamer, "[...] a experiência, nessa perspectiva, necessita da credencial de vivência própria, tendo em vista que só se atualiza nas observações (vivências) individuais e não pode ser conhecida em uma universalidade prévia”. 
Ainda nessa etapa da aprendizagem, podemos também pensar no que disse Merce Cunningham $^{5}$, a respeito do que seria experimentar. Mais do que formas, trata-se de fluxos de movimentos. Ensaiando uma sequência de movimentos e verificando que a energia passa, o bailarino encontra-se diante de múltiplas possibilidades de outros movimentos. Ensaia, escolhe, e assim, sucessivamente, criando um fluxo de energia (GIL, 2004).

Dessa forma, toda vez que passávamos pela aprendizagem de uma série de movimentos, como consequência desaguávamos na "transcendência de limites pela criação/invenção" (KUNZ, 2012), uma vez que solicitávamos que as crianças resignificassem suas aprendizagens, reelaborando, desdobrando e transformando os movimentos. Costumávamos dividir o grande grupo (mais ou menos vinte crianças) em pequenos grupos de cinco. Feito isso, solicitávamos que o pequeno grupo criasse três movimentos e os intercalasse na série aprendida. Na continuidade, reunia dois grupos de cinco, totalizando um grupo maior de dez crianças. A próxima tarefa era para que cada grupo de cinco ensinasse ao grande grupo de dez as sequências inventadas por eles próprios nos grupos menores. Em outro momento, tinham a tarefa de reelaborar esses movimentos alternando os níveis (médio/baixo/alto). E, assim, as crianças seguiam aumentando os seus repertórios de gestos e as possibilidades inventivas. Percebíamos, nesse momento, certo entusiasmo das crianças; era fantástico assistirmos, como se colocavam no lugar de ensinar e de aprender com o outro.

Nesse processo, era possível perceber que os repertórios dançantes não se caracterizam pelo seu fechamento, mas justamente, pela sua abertura, já que podem ser sempre articulados, modificados e reescritos infinitas vezes. A troca ampliava o poder de significar, produzindo jogos de sentidos experimentados na ação, no qual uma nova sequência de movimentos invadia as experiências dançantes.

Ficávamos observando como elas se contaminavam pelos gestos uma das outras. Quando alguém, em uma atividade disposta em grupo, realizava um gesto, víamos que o próximo a trazer uma sugestão carregava um pouco do outro, mas já sendo outro. Percebíamos que não havia a intenção em reproduzir cópias. Era uma ação em que elas não detinham o controle do gesto, e no momento do ato imprevisível carregavam o outro sem dar-se conta - pensamos que isso se dá também na escrita-, até que chegava um momento de ruptura. Havia sempre alguém que levava o gesto para outra direção, mas sem perder o outro de seu horizonte. Sem exclusão, os gestos apareciam como impulso para a diferença.

\section{A CRIAÇÃO COMO TRÍPLICE RETOMADA: EU-OUTRO-MUNDO}

No encontro com o outro, passividade e atividade, pluralidade e singularidade permanecem acasaladas. A dança propicia a exploração ativa de uma região em que o equilíbrio dá lugar ao desequilíbrio. Ela expande o espaço entre controlar e ser controlado. Essa é a relação quiasmática que se constrói entre o mover-se ativamente e o deixar-se ser movido, pelas coisas, pelas pessoas, ou ainda pelo mundo (KOZEL, 2007).

Por isso, entre elo e ruptura, ao "se-movimentar", as crianças são também movimentadas, pelas outras, pelo contexto, e pela proposta em execução. Ao dar vida às criações, arrastam no horizonte, não somente seu repertório de movimentos, mas

\footnotetext{
${ }^{5}$ Bailarino e coreógrafo norte-americano, um dos representantes da contemporaneidade na dança.
} 
também a percepção do gesto do outro, a contemplação que se inicia com as primeiras impressões que se esboçam no silêncio do acolhimento, em suas ações perceptivas. Silenciosamente o outro as invade. Os movimentos se atravessavam. Corpos se transpassam. Uma busca espaços nas formas da outra, outra preenche espaços nas formas de uma.

Na continuidade de seus deslimites, percebíamos que as composições que surgiam em uma determinada aula nunca se encerravam ali, uma vez que as crianças em momentos subsequentes, em outras atividades, movimentavam esses traçados corporais. Contando com um trabalho corporal sensível adquirido ao longo dos encontros, conversavam com temporalidades distintas, traçando uma temporalidade original.

Como já observamos com Merleau-Ponty, o tempo não é objeto de nosso saber, não é acontecimento sucessivo (fragmentado), mas campo de presença. Com isso, não há rivalidade entre as dimensões temporais, o que faz do surgimento do tempo presente, sempre um recomeço, no qual passado, presente, futuro são indivisos, envolvidoenvolvente (MERLEAU-PONTY, 2007). Sob este olhar, o original está no encontro das crianças com os outros e com a dança, no como experienciam o tempo, como se relacionam com as dimensões temporais já passadas e, a partir daí, anunciam um tempo singular com o vigor de quem se inventa no gesto. Especulando os movimentos já incorporados, havia uma repetição que era prazerosa, que integrava o tempo de brincar, no qual o repetir é sempre a cada vez. E, da mesma forma, havia criação de outros gestos, em que já não saberíamos identificar as origens e as múltiplas direções.

O "se-movimentar", entendido a partir da temporalidade encarnada, nos ajuda a pensar numa prática de ensino que não opõe as transcendências de limites da aprendizagem (forma direta, forma aprendida, forma criativa inventiva). O aqui-agora atravessa temporalidades, e para além da simples divisão - imitação, espontaneidade e criação - há o caminho do meio. O Jogo da transitividade entre elas.

Talvez aqui também possamos utilizar a proposição de Manoel de Barros, sobre o "criançamento" das palavras, para fazer referência ao "criançamento" dos gestos na infância. As crianças fazem dos movimentos o que o poeta fazia das palavras: brinquedo. Aprendemos com Manoel de Barros (BARROS, 1998, p. 64) que "[...] para voltar à infância, os poetas precisariam também de reaprender a errar a língua". E talvez seja isso também o que tenhamos de aprender com as crianças: perder o interesse em fazer algo estereotipado, "grandioso" e espetacular na dança. Algo que, a nosso ver, em parte a dança contemporânea já vem buscando e materializando. Há um instante em que o menos é mais, e os desconcertos, os erros, os despropósitos são recursos férteis para a imaginação criadora. Daí que, "[...] com certeza, a liberdade e a poesia a gente aprende com as crianças" (BARROS, 2013, p. 453).

Trabalhando com elas, descobrimos a beleza do entregar-se para a verdade do instante. Nisso elas são peritas. Na experiência de suas verdades, há um estado de presença invejável. Esse que encontramos no pensamento da dançarina Denise Stutz, quando em sua oficina "Corpo Presente", nos instiga a pensar "sobre o estado de presença que uma criança desenvolve ao jogar" (LEITE, 2014) e, ao relatar seu interesse pelo estado da infância em suas pesquisas de movimentos, logo nos propõe "[...] jogos que causaram transformações no corpo, fazendo-o estar presente, sem buscar a necessidade de presença. Essa 'não preocupação' em atingir um determinado estado corporal seria capaz de gerar organicidade em quem executa o movimento" (LEITE, 2014). 
Se concordarmos que "a infância é a camada fértil da vida", aceitamos que as crianças têm maior afinidade com o recomeço, e por não gostarem de gesto acostumado, até mesmo a repetição na brincadeira é como se fosse sempre pela primeira vez, sobre isso elas têm profundidade. Experimentam-se, aventuram-se, desafiam-se e "[...] neste mundo não há um propósito fora dos atos, não há objeto a ser apreendido ou conquistado" (VALÉRY, 2011, p. 10), por isso guarda-se proximidade com o "estado de presença" desejado pelos dançarinos. Entretanto, não podemos cair na ilusão de pensar que esse instante seja atemporal, sem passado, sem futuro.

Se recapitularmos que Merleau-Ponty para refletir sobre a linguagem, correlaciona historicidade (tempo), percepção (corpo), expressão (movimento/dança), e se olhamos o "se-movimentar" por essa perspectiva, conferimos que nenhuma das transcendências de limites pelo "se-movimentar" são alheias ao tempo. Assim como a linguagem, o movimento se dá no tempo. As aquisições de significados motores carregam o mundo em partilha, na relação embaralham o eu-outro-mundo, e não se fecham em si mesmas, podendo então ser acessadas a partir do exercício perceptivo do presente, que as reabre, instituindo, fundando uma temporalidade singular.

E, assim, como no uso das palavras, mais que a soma de significados determinados, elas fazem brotar sentidos na expressão do presente. Pelo contato, pela imediatez do instante, há motricidade original, porém atada ao "arco intencional" que se projeta entrecruzando passado-presente-futuro (quiasma), fazendo com que a criança se situe a partir de todas essas dimensões temporais e, portanto, de todas suas referências motoras. Se, o "se-movimentar", seja na dança ou em qualquer outra forma de expressão, não existe como objeto, mas sim como ação, como evento, ele nunca se fecha, é potência de significar, promessa de acontecimento.

Assim como Merleau-Ponty (1991) nos ensinou com o exemplo da linguagem, indicando a possibilidade de surpreendermo-nos sempre, de novo, com as palavras, as crianças podem sempre surpreender-se com a apreensão de movimentos na dança, descobrindo-se infinitamente neles. A "função conquistadora" da linguagem, realçada por Merleau-Ponty, abre caminhos, direções e dimensões para o movimento, e, portanto para a imaginação criadora. Entre o dançado e o dançante abre-se uma deriva; fissuramos os gestos e a imperfeição que evocamos revela no encontro a diferença pela continuidade. Por isso, a criação "original", não escapa da vulnerabilidade do eu, ao mundo e aos outros. E, se tem algo que aprendemos com Merleau-Ponty é que a criação envolve sempre a tríplice retomada: eu, outro, mundo.

Por fim, quando falamos em experiência do movimento, compactuamos com a formulação de Bracht (2012) quando expõe que, até é possível falarmos em "pensar com o movimento", o que confirma sua abertura numa exploração que ultrapassa seus próprios limites. Todos sabem que não há limites para o pensamento. Entretanto, se não há pensamento sem palavra, "[...] ao invés de utilizar a palavra 'pensar' (muito vinculada à ideia de conhecimento como algo restrito ao plano cognitivo) podemos ampliar para a noção de fazer experiências com o movimento" (BRACHT, 2012, p. 12).

A experiência da linguagem (ou da palavra) que se materializa em nossos gestos, guarda proximidade com a experiência do movimento, dada a imperfeição quando essas vêm à expressão. Como nos orienta Manoel de Barros "[...] as palavras se sujam de nós na viagem" (BARROS, 2013, p. 354), nelas guardamos os desconcertos, os deslimites. Portanto, nos interessa a vizinhança da vida expressiva dos gestos, na medida em que quando as tornamos acessíveis e visíveis aos outros, fazem-se cúmplices de sentidos ambíguos, plurais, e rebeldes.

\footnotetext{
${ }^{6}$ Nicolas Behr citado por Manoel de Barros (BARROS, 2013, p. 436).
} 


\section{REFERÊNCIAS}

ALMEIDA, L. Linguagem e experiência: pensando a educação física na escola republicana. 2016. 95 f. Tese (Doutorado em Educação nas Ciências) - Universidade Regional do Noroeste do Estado do Rio Grande do Sul, Ijuí, 2016.

ALMEIDA, L.; FENSTERSEIFER, P. E.; BRACHT, V. Experiência. In: GONZÁLEZ, F. J.; FENSTERSEIFER, P. E. (Orgs.). Dicionário crítico de educação física. 3. ed. Ijuí: Ed. Unijuí, 2014. p. 297-302.

BARDET, M. A filosofia da dança: um encontro entre dança e filosofia. São Paulo: Martins Fontes, 2014.

BARROS, M. A Poesia completa. São Paulo: Leya, 2013.

BARROS, M. O guardador de águas. 2 ed. Rio de Janeiro: Record, 1998.

BERNARD, M. De la création chorégraphique. Paris: Centre National de la Danse, 2001.

BRACHT, V. Corpo, movimento, conhecimento, educação e educação física: uma exploração filosófica. 2012. 53 f. Tese (Pós-Doutorado em Educação) - Programa de Pós-Graduação em Educação, Universidade Federal de Santa Catarina, Florianópolis, 2012.

DANTAS, M. Dança: o enigma do movimento. Porto Alegre: Ed. Universidade/UFRGS, 1999.

FENSTERSEIFER, P. E.; PICH, S. Ontologia pós-metafísica e o movimento humano como linguagem. Impulso, v. 22, n. 53, p. 25-36, 2012.

FRALEIGH, S. H. Dance and the lived body. A descriptive aesthetics. 2. ed. Pennsylvania: University of Pittsburgh Press, 1996.

GADAMER, H. G. Verdade e método I: traços fundamentais de uma hermenêutica filosófica. Tradução de Flávio Paulo Meurer. 12. ed. Petrópolis: Vozes, 2012.

GHIDETTI, F. F. A teoria do "se-movimentar" humano (TSMH) em questão: limites e possibilidades para uma teoria da educação física. 2012. 175 f. Dissertação (Mestrado em Educação Física) - Programa de Pós-Graduação em Educação Física, Universidade Federal do Espírito Santo, Vitória, 2012.

GIL, J. Movimento total: o corpo e a dança. 2. ed. São Paulo: Iluminuras, 2004.

KOZEL, S. Closer: performance, techonologies, phenomenology. Massachusetts: Massachusetts Institute of Tecnology, 2007.

KUNZ, E. Educação física: ensino e mudança. 3. ed. Ijuí: Ed. Unijuí, 2012.

KUNZ, E. Transformação didático-pedagógica do esporte. Ijuí: Unijuí, 1994.

LANGER, S. K. Sentimento e forma. Tradução de Ana Maria Goldberger Coelho e J. Guinsburg. São Paulo: Perspectiva, 1980.

LEITE. L. Acreditar na brincadeira, como uma criança que leva o jogo a sério. In: MULTIPLA DANÇA. Festival Internacional de Dança Contemporânea. Múltiplas escritas. Disponível em: < http://multipladanca.webnode.com/programacao/multiplas-escritas/ >. Acesso em: 05 jul. 2014.

LOUPPE, L. Poética da dança contemporânea. Lisboa (Portugal): Orfeu Negro, 2012.

MERLEAU-PONTY, M. O visível e o invisível. São Paulo: Perspectiva, 2007. 
MERLEAU-PONTY, M. O olho e o espírito: seguido de A linguagem indireta e as vozes do silêncio e A dúvida de Cézanne. Tradução de Paulo Neves e Maria E. G. G. Pereira. São Paulo: Cosac \& Naify, 2004.

MERLEAU-PONTY, M. Fenomenologia da percepção. Tradução de Carlos A. R. Moura. 2. ed. São Paulo: Martins Fontes, 1999.

MERLEAU-PONTY, M. Signos. Tradução de Maria E. G. G. Pereira. São Paulo: Martins Fontes, 1991.

MERLEAU-PONTY, M. O homem e a comunicação: a prosa do mundo. Tradução de Celina Luz. Rio de Janeiro: Edições Bloch, 1974.

MÜLLER, M. J. Merleau-Ponty: acerca da expressão. Porto Alegre: EDIPUCRS, 2001.

PALMER, E. R. Hermenêutica. Lisboa: Edições 70, 2006.

SARAIVA, M. C. O sentido da dança: arte, símbolo, experiência vivida e representação. Movimento, Porto Alegre, v. 11, n. 3, p. 219-242, set./dez., 2005.

TIBURI, M; ROCHA, T. Diálogo/dança. São Paulo: Editora Senac, 2012.

VALÉRY, P. Filosofia da Dança. Tradução de Charles Feitosa. O Percevejo Online, v. 03, n. 02, ago./dez., 2011.

VALÉRY, P. Variedades. São Paulo: Iluminuras, 2007.

Recebido em: 6 set. 2017.

Aprovado em: 27 out. 2017. 